\title{
RITUAL OLÍMPICO E OS MITOS DA MODERNIDADE: IMPLICAÇÕES MIDIÁTICAS NA DIALÉTICA UNIVERSAL/LOCAL ${ }^{1}$
}

\author{
Fernando Gonçalves Bitencourt ${ }^{2}$, Cassia Hack ${ }^{3}$, \\ Antonio Galdino Costa ${ }^{4}$, Sérgio Dorenski Ribeiro ${ }^{5}$, \\ Mariana LisbôA ${ }^{6}$, Mellyssa Mól ${ }^{7}$, Cristiano Mezzaroba ${ }^{8}$, \\ Diego Mendes ${ }^{9}$ e Giovani Pires ${ }^{10}$
}

\begin{abstract}
RESUMO
Este artigo pretende discutir os Jogos Olímpicos de Atenas como um ritual que organiza e estrutura as narrativas míticas que constroem a modernidade. Reflete sobre o papel dos meios de comunicação de massa na disseminação destas narrativas por meio da divulgação massiva deste ritual, produzindo um processo de identificação dos sujeitos através de estratégias específicas, colaborando na fragmentação das identidades e na cisão entre cultura subjetiva e cultura objetiva, o que, conforme Simmel, configuraria-se na tragédia da cultura. Como base documental, são utilizadas matérias jornalísticas de dois jornais de Santa Catarina a respeito da participação dos atletas catarinenses olímpicos.
\end{abstract}

PALAVRAS-CHAVE: mito - ritual - cultura - esporte - mídia.

1 Versão preliminar deste texto foi aprovada para apresentação no II Congresso Sul Brasileiro de Ciências do Esporte, em Criciúma/SC, de 7 a 9/10/2004.

2 Professor do CEFETSC - Unidade São José e doutorando em Antropologia Social/ PPGAS/UFSC.

3 Professora da Rede Estadual do Mato Grosso e mestranda em Educação Física/UFSC.

${ }^{4}$ Professor do CEFETSC - Unidade São José e mestrando em Educação Física/UFSC.

5 Professor do DEF/UFS e mestrando em Educação Física/UFSC.

6 Licenciada em Educação Física e pós-graduanda em Educação Física Escolar/NEPEF/ UFSC.

7 Jornalista e acadêmica do curso de licenciatura em Educação Física/UFSC.

8 Acadêmico do curso de licenciatura em Educação Física da Universidade Federal de Santa Catarina e bolsista do Grupo PET/EF/UFSC.

9 Acadêmico do curso de licenciatura em Educação Física da Universidade Federal de Santa Catarina e bolsista do LABOMIDIA/CDS/UFSC.

${ }^{10}$ Professor do DEF/CDS/UFSC e coordenador do Grupo de Estudos Observatório da Mídia Esportiva/UFSC. 


\section{INTRODUÇÃO}

$\mathrm{V}$ ivemos, recentemente, mais uma vez, tempos de Olimpíadas. De volta à Grécia, os Jogos se reencontraram com a história e tentaram reconstruir e projetar o "sonho" olímpico para um devir inestimável. Ao voltar ao berço, refez-se um percurso poético produzido pelas versões de narrativas eleitas dignas para alcançar a "todos", expondo à luz, ao mesmo tempo, mitos importantes para o entendimento dos tempos atuais, que se cristalizam numa Modernidade emergida com o Renascimento. Este evento de múltiplas linguagens, atualização de expectativas humanas há muito erguidas, tomou de assalto a vida cotidiana e remeteu uma multidão de espectadores e blasées ao esporte e sua pantomima. Como recorrência simbólica, mais do que ação, o que tivemos foi narração.

Para adentrarmos neste universo, podemos tomá-lo de vários ângulos. Os apologistas aguardavam os grandes feitos, as vitórias emocionantes e a tristeza desgraçada do fracasso. Outros, investidos de orgulho nacionalista, esperaram ansiosos a participação de seus países, a contabilizar medalhas em comparação com o passado e o vizinho, prometendo melhor sorte e mais investimentos no futuro. Outros, fustigaram os avanços científicos e tecnológicos que produziram resultados surpreendentes, assim como tantos outros estiveram ligados na "traição" trapaceira do doping. Estas questões também merecem um olhar atento e crítico. Nosso caminho, aqui, é outro, mas tomando os mesmos objetos.

Um paradoxo estimula a imaginação, inquieta e nos faz refletir sobre as características que marcam este evento. Ele pode ser pensado de um prisma inicial que liga o tempo ao espaço, a narrativa à ação, o mito ao ritual. Pensemos um pouco sobre a questão.

A Modernidade - e a globalização como seu corolário - pode ser, em sentido específico, entendida como processo de aceleração do tempo e o conseqüente encolhimento do espaço, em virtude desta aceleração e devido à velocidade de deslocamento propiciada pelos meios de transporte e informações, em linhas gerais, fruto do aperfeiçoamento da tecnociência. Decorrente desta aceleração, uma série de desarticulações parece atingir as subjetividades, que tem levado à fragmentação do sujeito e ao esgarçamento do tecido social, resultando em certa 
esquizofrenia e na perda de sentido. Entretanto, as pessoas dizem parar para ver as olimpíadas. Como é possível parar? Em que sentido isto se dá, na medida em que a velocidade aumenta?

Se há um encolhimento do espaço em relação ao tempo, vimos no tempo Olímpico o espaço se expandir ao máximo. Atenas alcançou o globo. Um pequeno lugar alargou-se na escala planetária e imiscuiu-se nos recantos mais distantes, onde houvesse uma antena, um rádio, uma televisão. Todos estivemos em Atenas, ou melhor, Atenas estava em nós, de muitos ângulos, diversas perspectivas, inúmeras narrativas. Como o espaço pode se expandir a ponto de nos alcançar? Como Atenas pôde fazer para nós, de qualquer outro lugar, algum sentido em termos de lugar?

Estas questões, articuladas em torno do aqui e agora e da velocidade de deslocamento, têm seu suporte, é claro, na tecnociência. Mas reveste-se de elementos simbólicos importantes, radicados na correlação mito e rito - narrativa e ação - que são os fundamentos dos argumentos que lançamos para discutir o paradoxo levantado, e de como, vivendo num tempo/espaço diferente do olímpico, construímos estratégias de nos vincularmos ao discurso universal, de sermos também modernos e de fazermos parte desta identidade planetária construída em torno dos Jogos Olímpicos de Atenas/2004.

Nestes termos, este artigo pretende articular uma análise macrossociológica do evento olímpico ao processo jornalístico que visa incluir o local no universal, através de estratégias discursivas que relacionem o evento de ordem global ao local e, por que não, ao mais íntimo do indivíduo, sua subjetividade. Nossa referência para entendimento deste processo são dezenove atletas olímpicos catarinenses e, como caminhos desta narrativa, escolhemos a mídia impressa, representada por dois dos principais jornais diários de circulação estadual, em Santa Catarina, o Diário Catarinense (DC), editado em Florianópolis, e o A Notícia (AN), de Joinville. O período de observação corresponde ao mês de agosto de 2004, sendo possível observar que um dos jornais (DC), além das notícias da tradicional editoria de esportes, produziu um caderno especial (Atenas 2004) que circulou diariamente de 11 a 30 de agosto.

O primeiro procedimento foi a leitura de todo o material coletado e a localização de notícias relativas aos atletas catarinenses, sendo elaborada uma matriz analítica quantitativa na qual foram registradas as referências 
a cada atleta. ${ }^{11}$ A seguir, identificamos, em cada jornal, os atletas com maior número de registros, respectivamente: a) no $D C$ - Gustavo "Guga" Kuerten (tênis), Fernando "Xuxa" Scherer (natação), André "Bochecha" Fonseca (vela) e Fabiana Beltrame (remo); b) no AN - Guga, Fabiana Beltrame, Xuxa, além de José Alessandro Baggio e Alessandra Picagevicz, ambos da marcha atlética. ${ }^{12}$

A etapa seguinte foi a análise interna das manchetes e do conteúdo das matérias relativas a estes seis atletas catarinenses, visando a caracterizar as narrativas jornalísticas através das quais a mídia impressa do Estado elaborou um discurso significativo para a criação de identidade e colocou o evento universal no cotidiano dos catarinenses, por meio do destaque dado a estes ídolos olímpicos locais. Exemplos deste processo são apresentados neste texto, especialmente no último tópico.

\section{RITO E MITO}

As análises antropológicas sobre mito e rito caminham por diversas perspectivas, que, é claro, não cabe aqui destacar. De todo modo, duas formas de análise investem-se de importância, a saber: a primeira forma reconhece uma relação entre os rituais e os mitos no que poderíamos chamar de complementaridade circular e a segunda, pensa os rituais e os mitos como eventos separados e não necessariamente complementares. Para o que nos cabe, tomamos aqui a primeira assertiva. Com isso, separamo-nos de análises que procuram no mito as formas profundas da mente humana e reconhecemos, nestas narrativas, modelos explicativos para a vida social, ou, de maneira mais ampla, para o entendimento cosmológico do mundo das diferentes culturas.

Entendendo que rituais e mitos encerram uma correlação, trataremos primeiramente da idéia de ritual para, em seguida, refletir em que sentido os mitos inscrevem-se na ordem ritual e os reforçam.

Os rituais, segundo Rivière (1996), são eventos que se repetem com certa freqüência, geralmente de modo cíclico e de modo geral cumprem três funções principais: a) introduzir um elemento separado do conjunto social no grupo, abrindo ao integrado a participação na identidade coletiva, como sugere os inúmeros ritos de iniciação e de passagem que conformam a vida social; b) resolver momentos de crise ao fazer reencontrar num todo harmonioso, através de sua simbologia, as partes 
conflitantes ou elementos em desencaixe e; c) manter a estrutura social através de eventos cíclicos que simbolizem a coesão social, o sentimento de pertença e configure a identidades individuais e coletivas.

Estas funções apresentadas não esgotam as análises sobre o ritual, mas são, em nosso caso, os elementos que podemos destacar para gerar a coerência textual que buscamos nessas análises. Sendo assim, reafirmamos que, para estes casos, os mitos, narrativas que pretendem dar alguma coerência ao mundo - por exemplo, sobre sua gênese ou sobre sua permanência estrutural para determinados grupos -, não são, com efeito, unívocos e idênticos e estão sujeitos a reformulações em determinados contextos.

Leach (1996) nos mostra, ao estudar os sistemas políticos da Alta Birmânia, como o mesmo mito, narrado para configurar uma estrutura social, podia ser utilizado por opositores políticos, sob os mesmos termos mas com interesses que transformavam a narrativa em seu favor. Nestes termos, um mito de origem podia ser empregado por diferentes atores sociais em circunstâncias específicas que os beneficiasse, sem, contudo, perder o essencial contido nos elementos estruturais da própria narrativa mítica. Com esta demonstração, Leach evidenciou o uso político dos mitos e seu poder de construir a realidade em consonância com interesses privados ou coletivos.

A Modernidade é carregada de narrativas míticas e de rituais que ciclicamente respondem pela necessidade de se confirmar estes mitos e estruturar a realidade social de um prisma concebido como moderno. Nosso próximo passo será apresentar as principais narrativas que compõem a modernidade e examinar um ritual importante para a sua estruturação.

\section{MODERNIDADE E GLOBALIZAÇÃO: NARRATIVAS}

A Modernidade, reinvenção do passado articulada pelo Renascimento e pelo Iluminismo, tem seu principal fundamento ancorado no uso da razão. Mas ela é um tanto mais plural e, concebida sob esta bandeira, ainda incorpora elementos do monoteísmo cristão e elementos recorrentes ligados à natureza. Esta tríplice formulação pode ser resumida nas questões antropológicas que perseguem o ser humano - ou que o ser humano persegue: natureza, cultura e sobrenatural. 
Sabemos que a Modernidade, por princípio, está ligada a uma nova episteme, conforme sugere Foucault (1992), que viria classificar e organizar o mundo sob os auspícios das ciências matemáticas, médicas, jurídicas entre outras. Mas esta classificação, que põe o humano no centro do universo, vai estruturar-se com o advento da industrialização e crescente urbanização das cidades, com a burocratização das organizações estatais, com a secularização, com o avanço da técnica e da ciência e, conforme Waizbort (2000), citando Simmel, com a disseminação do dinheiro como forma abstrata de medir o valor das coisas.

Entretanto, esta crescente racionalização não será capaz de impedir a fé em um Deus que é e que, em seu poder demiúrgico, vai continuar a controlar e a organizar o tecido social. Assim, concomitante ao advento da ciência e seu poder de explicação do mundo, as Igrejas, representantes do poder divino na terra, continuam a responder por uma série de questões existenciais que assombram a vida humana. Adorno e Horkheimer (1985) nos lembram que a ciência se converte em novo mito (religião) e que, em última instância, o poder da ciência é fundado sob a fé em suas realizações.

Do mesmo modo, a natureza permanece viva na Modernidade, seja ela pensada como fora de nós e como um problema ecológico a ser resolvido, ou seja, a própria natureza humana, inscrita em nossa corporalidade e psique, e que suscita profundos debates em torno do que é ser humano. A natureza, interna ou externa, aparece como, por um lado, ponto de equilíbrio para um resgate do propriamente humano e, por outro, empecilho ao avanço infinito do progresso científico-tecnológico.

Esses três elementos que estruturam a vida moderna estão sob as pressões dos mitos de fundação destes dias em que vivemos e que têm, na idéia de progresso infinito, base narrativa de um positivismo que se imiscui no capitalismo ora neoliberal e de um discurso universalizante e que precisa ter em sua agenda ritos que atualizem seus ideais e fortaleçam a identidade planetária em torno destes pressupostos.

Reconhecemos, entretanto, profundas contradições nesta Modernidade na qual o capitalismo tornou-se hegemônico e que, em sua versão globalizante - efeito operado, como mencionamos na abertura, pelos velozes meios de transporte e comunicação -, nos impõem uma aceleração brutal da vida, encolhendo o espaço em relação ao tempo, implicando em alterações profundas em nossa sensibilidade e em nossas subjetividades. 
Este mundo que se articula em torno do capital, que se expande através do consumo e se encolhe em termos de posse de capital e é fustigado pela violência, precisa então formular discursos homogeneizantes, que integrem os mais distantes e excluídos à comunidade planetária.

Entretanto, os deslocamentos causados pela aceleração constante e a perspectiva de progresso infinito via tecnologias têm gerado a fragmentação das identidades, conforme assinala Hall (2003), gerando diferentes posições sociais, nas quais os sujeitos precisam se reconhecer, e que não fornecem a segurança de um Eu único, mas um processo esquizofrênico de construção da identidade. Segundo Harvey (1992), a Modernidade caracteriza-se por um infindável processo de fragmentação e rupturas em seu interior, o que deixa o indivíduo e o tecido social repleto de fissuras, fraturas e cortes abertos que devem ser preenchidos, normalmente, pelas mercadorias.

Se a Modernidade veloz constrói esta fragmentação, ao mesmo tempo precisa criar mecanismos que suportem suas narrativas míticas e reorganizem a sociedade numa identidade menos flutuante. Este suporte tem sido, junto com as mercadorias - e/mas como mercadoria - o esporte. Trataremos deste ponto a seguir, ao abordarmos os Jogos Olímpicos como um dos vários rituais que se desenvolveram para os fins acima mencionados.

\section{JOGOS OLÍMPICOS: RITO PROFANO E MITO}

A reinvenção dos Jogos Olímpicos no final do século XIX acabou por articular a Modernidade à Grécia, algo que, como já vimos, o Renascimento e o Iluminismo já haviam tratado de realizar. Mas tal evento não ressurge apenas como o sonho encantado de um visionário; ao contrário, é fruto do espírito do tempo e dele carrega e amplia seus significados. A Olimpíada da era moderna é, para citar Mauss (1974), um fato social total. Nela, cultura, política, economia, direito, história, religião, se encontram formando um todo complexo, que abarca as diferentes esferas da vida social, elementos componentes de uma Modernidade que, em sua velocidade e aceleração, permanece, paradoxalmente, a mesma.

Rivière (1996) chamaria os Jogos Olímpicos de ritual profano, pois desvinculado das questões especialmente religiosas teria sua realização 
vinculada a interesses ligados à estruturação e à organização da vida social, neste caso, em escala planetária. Nestes termos, realizadas de quatro em quatro anos, sob a bandeira da paz e integração dos povos e sob o lema mais rápido, mais alto e mais forte, as Olimpíadas configuram-se como um ritual moderno no qual as narrativas desta Modernidade se atualizam. Neste aspecto, os jogos funcionam como elemento simbólico catalisador de idéias modernas e aglutinam em torno de si os olhares dos sujeitos espalhados pelo globo em suas coletividades.

Vejamos algumas articulações entre os Jogos Olímpicos enquanto ritual e as narrativas míticas que fundam a Modernidade. Tomaremos apenas quatro pontos para não nos alongarmos na questão:

a) A Modernidade pretende-se um discurso universalizante, logicamente a partir de um ponto de vista ocidental - inicialmente eurocêntrico e agora também americanocêntrico - e baseado na idéia de paz e confraternização entre os povos. Nestes termos, os Jogos abarcam hoje duzentos e oito países, tendo na cerimônia de abertura e durante os jogos as bandeiras dos países, os símbolos da paz e da congregação dos continentes em elos de cores representativas como epítome do evento. ${ }^{13}$ Marca também o evento, o discurso do jogo amigável e limpo (fair-play), além da idéia de que o importante é participar. Assim, atletas convidados, sem nenhuma possibilidade atlética de competir nos níveis exigidos, estarão presentes como fantasias desta realização.

b) Celebrando o mito do progresso infinito, este rito é marcado pela expectativa da quebra de recordes de força, velocidade e altura, e aposta em todas as possibilidades para que estes objetivos sejam alcançados. Por um lado, aposta-se na natureza aguerrida, lutadora e vencedora do ser humano, uma natureza que nos faz transcender, vencer obstáculos (adversários ou inimigos). Por outro, espera-se, do mesmo modo, que os deuses interfiram no resultado e abençoe um vitorioso, de preferência com uma performance inesquecível e, mais importante, aposta-se na tecnociência, através do desenvolvimento do treinamento desportivo, dos equipamentos e instalações, do regime nutricional e dos mais sofisticados métodos tecnológicos para a melhoria da performance (inclusive o doping) para que se realize o avanço das marcas e se confirme e atualize o mito. 
c) Apresenta-se também em relevo um discurso moral, ligado aos valores ocidentais da justiça e da ética. O uso de substâncias ilegais, o doping, é a síntese ritual da moral capitalista, na qual os esforços para se proteger a propriedade privada e a luta contra a violência e o roubo são ataques aos menos desfavorecidos. Deste modo, países ricos - em capital econômico e cultural - usariam seu potencial técnico-científico para burlar as regras sem serem descobertos, algo praticamente impossível aos outros países em condições desfavoráveis em termos econômicos e políticos. ${ }^{14}$

d) Por fim, refaz-se o discurso liberal capitalista da igualdade de chances e do "que vença o melhor!". O esporte, de modo geral, e as Olimpíadas em particular - pois atraem os olhares do globo - reforçam em nossas subjetividades o espírito individualista da contemporaneidade, caracterizado por uma profunda desigualdade social, política, cultural e econômica, mas que é encoberta pela idéia de que todos nascemos livres e iguais perante a lei e perante Deus. Sob o disfarce do talento, da fé e do trabalho, imprime em nossas vidas o peso do fracasso, que deve ser entendido como natural e, portanto, legítimo.

Estes são alguns elementos que sugerem as relações estreitas entre as narrativas míticas modernas e que encontra nos Jogos Olímpicos um ritual importante para inscrever seus significados na sociedade, através do uso simbólico, metafórico e por que não poético que é atribuído aos esportes, aos esportistas e às suas façanhas.

\section{MÍDIA E OLIMPÍADAS: A FORMULAÇÃ̃O DA IDENTIDADE/IDENTIFICAÇÃO}

Como mencionamos anteriormente, os Jogos, que acontecem em um espaço restrito, mas num tempo que poderíamos chamar de virtual, precisam, em sua lógica, atravessar as fronteiras internas de sua realização por atletas, árbitros, etc., e transformar-se em um discurso que atinja os sujeitos em seus espaços de sociabilidade. Deste modo, os meios de comunicação seriam os responsáveis por transformar os atos em narrativas, o ritual em mito e realizar as funções rituais que descrevemos, a saber: coesão, harmonia e construção e manutenção da identidade coletiva universal. 
Lidar com a identidade, como vimos, não é tarefa fácil, pois, segundo Appadurai (2001), o esforço para se manter espaços locais como suportes da identidade esbarra na crescente ruptura entre território, subjetividade e movimentos sociais, devido aos processos de transnacionalização da experiência (e os movimentos diaspóricos de vários níveis) e da ação dos meios de comunicação. É neste complexo que o local e o universal estão estruturalmente ligados. A Mídia, então, parece operar a relação local-universal agenciando discursos diversos, entre eles o esportivo, para tal efeito. Recorrendo ao sentimento de pertença ligado a um atleta local - preferencialmente se este é também um ídolo transnacional - provoca a identificação do local com o universal e a incorporação, em nosso caso pelo local, do discurso ideológico universalizante constituído pelo esporte olimpicamente ritualizado.

Recorrendo a esta estratégia, temos recortes discursivos importantes nos jornais, que promovendo, agendando e noticiando atletas catarinenses nos Jogos, promovem o efeito de identificação discutido, conforme podemos notar nos textos abaixo.

Com 19 representações em Atenas, os catarinenses terão motivos de sobra para não tirar os olhos a TV, durante os 17 dias em que serão realizados os jogos olímpicos (DC, 11/08/04, p. 6 - "Os Catarinenses em Atenas").

Um dos maiores ídolos de todos os tempos, o catarinense Gustavo Kuerten também estará em Atenas. O tenista colocou como prioridade na temporada, a participação na olimpíada, garante que dará o máximo [...] Guga será uma das sensações na Vila Olímpica (DC, 11/08/04, p. 7 - “Os Catarinenses em Atenas").

Os catarinenses Fabiana Beltrame e Anderson Nocetti ficaram satisfeitos com seus resultados no primeiro dia de disputas de remo, no sábado (DC, 16/08/04, p. 3 - “Catarinenses Felizes com Resultados”).

Nestes termos, também, apontamos a idéia de que os sujeitos sociais param para assistir aos Jogos Olímpicos. Esta sensação de estar parado apenas serve como baliza para a aceleração que se opera quando um evento desta natureza se realiza. Se o "mundo" pára para ver os jogos, o mesmo mundo é pura velocidade de informações, de mercadorias, 
de capital e de fluxo de pessoas em diferentes direções. O olhar convergente tem como reação o retorno implacável das narrativas modernas que aceleram os tempos atuais.

Parece-nos que a idéia de um "presente perpétuo"15 (JAMESON, 1997), que não está em contradição com a idéia de progresso, é a própria expressão do ritual olímpico e do sonho esportivo fetichizado. O tempo olímpico reificado é a síntese de um devir controlado, um constante movimento de necessidades criadas que projetam o futuro sobre o presente, gerando a sensação do acontecimento eterno. As expectativas geradas, na vitória ou na derrota, não projetam ações para o futuro, mas recuam o tempo do devir para o instante simbólico construído no discurso presente.

Anderson Nocetti, [...] e Fabiana Beltrame vieram para a Grécia em busca de bons resultados, mas não escondem que a experiência será ainda mais valiosa para o Pan-Americano de 2007, no Rio de Janeiro (DC, 13/08/04, p. 3 - "De Olho no Futuro").

Tenista está disposto a desafiar as dores e já pensa nos jogos da China (DC, 17/08/04, p. 3 - "Não Deu Para Guga").

Fernando Scherer já pensa no Pan de 2007 (Título da matéria publicada em AN, 20/08/04, p. A13).

Parados no tempo, Atenas vem até nós. Junto com este espaço que a mídia constrói em seus muitos ângulos e inúmeras perspectivas, somos invadidos por este universo simbólico, o qual produz o universal e nos faz sentir parte integrante desta comunidade. Entretanto, esta é uma estratégia, em primeiro plano, simples. Ela se radicaliza quando passamos da identidade para a identificação, processo que coloca o sujeito em articulação sensível com o objeto identificável e dificulta sua possibilidade reflexiva, embotando o olhar.

Este processo de identificação constrói-se sob uma estrutura um tanto dramática das narrativas que configuram a Modernidade, o que implica certo formalismo nos mitos, onde os conteúdos são arranjados numa seqüência que ordene os fatos significativamente. Deste modo, o final feliz está sempre precedido das dificuldades a enfrentar - seja o trabalho árduo, seja a dor e o cansaço, seja a falta de patrocínio - que ainda remete a um passado no qual tudo era tranqüilidade. Ficção ou realidade, as tramas 
parecem indicar sempre o mesmo esquema narrativo. Assim, em reportagem do DC sobre Guga, temos a descrição do seguinte drama:

Guga deixou a quadra número um do complexo de tênis da vila Olímpica de Atenas, ontem, de cabeça baixa e em silêncio. Ainda ouviu aplausos do público, mas não ligou. Caminhou uns cem metros e se fechou no vestiário. Ficou lá pelo menos uns quarenta minutos, pensando na derrota para o chileno [...] e no fim do sonho de disputar a medalha de ouro [...] - "Não sou mais o mesmo de antes, nunca mais terei condições de fazer tanto quanto antes". - Falou, ao se referir aos problemas físicos que enfrenta há pelo menos dois anos. A entrevista foi uma espécie de desabafo. Guga disse que cada vez que decide curtir sua paixão pelo tênis, sabe que enfrentará um período de sofrimento físico [...] - "Tenho de buscar saídas, este é o teorema da minha vida." Fim de carreira nem pensar. Além de ter ainda meros 27 anos, Guga não poderia ficar sem o tênis de sua vida [...] O homem que um dia saiu de Floripa para ser o número um volta agora para casa, curtir suas praias preferidas, a família e descansar (DC, 17/8/04, p. 3 - "Não deu para Guga").

Na mesma perspectiva, mas com uma trama que mistura sofrimento, esperança e confiança, o marchador José Alessandro Baggio afirma:

"É como qualquer trabalho, se não gostar não vai para frente. Eu amo a marcha atlética". Para quem já treinou de tênis furado, no início da carreira, se considera um privilegiado. - "Tenho patrocínio de tênis, para comprar material, vitaminas, suplemento. Para Pequim, com o resultado, vai melhorar ainda mais" (AN, 21/08/2004, p. A14 - "Esporte com pouco apoio no Brasil").

O mesmo aspecto pode ser lido na seguinte reportagem sobre Fernando Scherer:

Fernando Scherer ficou fora das finais dos $50 \mathrm{~m}$ e deixou o parque aquático de Atenas meio desapontado: "Fiz meu melhor tempo em Olimpíada e acabei ficando fora da disputa pela medalha. Agora, vou torcer pelo Gary Hall Jr.” [...] Os dois são amigos há dez anos, treinaram longo tempo na mesma academia nos Estados Unidos e eram parceiros nas horas de folga. A distância que os separou nesta Olimpíada, de menos de 20 centésimos, deve estar relacionada à troca de domicílio. Gary continuou nos

BITENCOURT, F. G. et al; Ritual olímpico e os mitos da modernidade ... 
EUA e Xuxa, por falta de patrocínio, retornou ao Brasil. "Aqui, comprovadamente, não temos as mesmas condições que os americanos oferecem aos seus atletas" (AN, 21/08/04, p. A14 - "Natação-Scherer”).

É nestes termos que a mídia de circulação local vai buscar no contexto amplo dos jogos e seus inúmeros atletas aqueles que mais se identificam com o local do qual a mídia fala, e dentre estes, os que podem obter os melhores resultados. Essas afirmações, que exigiriam estudo mais detalhado, algo que um ensaio apenas pretende apontar, podem ser notadas na insistência com que os jornais locais falam dos atletas de Santa Catarina - e no caso, também de Florianópolis - que participam da competição. Uma análise quantitativa destas matérias em comparação com outros temas e a conseqüente análise de conteúdo poderão nos indicar melhor como operam os meios de comunicação de massa nestes eventos.

Um ponto, entretanto, não deixa dúvida. Os meios de comunicação, ao criar a associação afetiva e imaginária de estarmos lá, competindo, através de conterrâneos, próximos ou distantes, deixam os sujeitos e as sociedades locais em conexão com o discurso universal amalgamado no universo simbólico/ritual dos Jogos Olímpicos e, ao mesmo tempo, difundem e colaboram para inculcar os mitos que este ritual reforça, produzindo, na trama de significados que é gerada no processo cultural, esta identificação com o universal, com os Jogos e com seus efeitos.

\section{ÚLTIMAS PALAVRAS}

Chamamos atenção aqui para uma (ou algumas) das inúmeras contradições que percorrem a Modernidade e se estende pelo campo cultural, político e/ou econômico. Entendemos viver em tempos cuja exploração capitalista atinge estágio perigoso e que há inúmeros riscos à vida na terra, os quais atravessam a existência humana sob inúmeros flagelos, tais como os da fome miserável, da ignorância e da guerra. Entendemos também, que sob o disfarce da paz, da comunhão entre os povos e do progresso da humanidade, interesses político-econômicos rasgam as Olimpíadas em um ritual que mistifica as inúmeras formas de exclusão e classificação que ainda nos embrutecem.

Os meios de comunicação de massa, ou são porta-vozes desta ilusão ritual, ou colaboram na reinterpretação e na construção de novos 
mitos, já que não é mais possível viver sem o poder de penetração dos meios no tecido social. Ao mesmo tempo, estratégias de recepção crítica precisam ser formuladas para que o discurso fácil da transcendência humana, através da sua superação performática infindável, continue a ser um veículo de alienação.

Simmel, citado por Waizbort (2000), identificou na Modernidade, em virtude do valor abstrato do dinheiro e da sua velocidade e facilidade de circulação - algo que Marx percebeu na alienação do produto do trabalho do trabalhador, mas que Simmel ampliou para toda a esfera da vida - a cisão entre a cultura subjetiva e a cultura objetiva. Para este autor, toda cultura subjetiva é objetivada na arte, na ciência, na política etc. O problema é que não há, na Modernidade, no contexto da vida urbana - veloz e fragmentada - o reencontro da cultura objetiva com a subjetividade dos sujeitos. Os objetos autonomizaram-se, tornando-se um fim em si mesmos. A reconciliação entre a cultura subjetiva e a cultura objetiva é a possibilidade de superar a tragédia da cultura. Adorno (1996) reelabora mais tarde esta questão sob o título de semiformação, preocupado com a vida danificada.

A interpretação inicial que este ensaio faz dos Jogos Olímpicos enquanto elemento ritual da Modernidade que visa a sua manutenção estrutural a partir de narrativas míticas com as quais o sujeito fragmentado deve se identificar é uma tentativa, ainda que bastante limitada, de expor a necessidade de reencontro entre as esferas da vida que se esfacelam e, mais ousadamente, uma tentativa de colaborar nesta direção.

The olympic ritual and the myths of modernity:

Mediatic implications in the local/universal dialectics

\begin{abstract}
This article intends to discuss the Athens 2004 Olympic Games as a ritual which organizes and structures the mythic narratives that build modernity. It reflects upon the role of mass media in the dissemination of these narratives through the massive showing of this ritual, thus producing an identification process of the subjects through specific strategies, contributing to the fragmenting of identities and the separation between subjective and objective cultures which, according to Simmel, would constitute the tragedy of culture. Articles from Santa Catarina state newspapers which dealt with the participation of local Olympic athletes are used as documented evidence.
\end{abstract}

KEY WORDS: myth - ritual - culture - sports - media.

34 BITENCOURT, F. G. et al; Ritual olímpico e os mitos da modernidade ... 


\section{Ritual olímpico y los mitos de la modernidad: implicaciones mediáticas en la dialéctica universal/local}

\section{RESUMEN}

Este artículo pretende discutir los Juegos Olímpicos de Atenas como un ritual que organiza y estructura las narrativas míticas que construyen la modernidad. Reflexiona sobre el papel de los medios de comunicación de masa en la diseminación de estas narrativas por medio de la divulgación masiva de este ritual, produciendo un proceso de identificación de los sujetos a través de estrategias específicas, colaborando en la fragmentación de las identidades e en la cisión entre cultura subjetiva y cultura objetiva, lo que, según Simmel, se configuraría en tragedia de la cultura. Como base documental, son utilizadas materias periodísticas de dos periódicos de Santa Catarina a respecto de la participación de los atletas catarinenses olímpicos.

PALABRAS-CLAVE: mito - ritual - cultura - deporte - medios.

\section{NOTAS}

11 Reconhecemos que o critério quantitativo de referências não seria o único possível para o recorte desejado, mas assim optamos em virtude da extensa quantidade de documentos disponíveis, o que dificultaria uma análise qualitativa de todo o material.

12 Nota-se, desde aqui, a importância do local no discurso midiático: enquanto o DC, da capital, destaca o velejador pertencente a um clube de Florianópolis, o AN, do norte do Estado, dá ênfase a dois atletas de Timbó, cidade da região do Vale do Itajaí, próxima a Joinville. Os outros três atletas - Guga, Xuxa e Fabiana Beltrame -, que se repetem nos dois jornais em número de registros, embora também "locais" (Florianópolis), têm ou tiveram destaque na mídia nacional, inclusive para além dos Jogos Olímpicos.

13 Todavia, para que os jogos celebrassem a paz, quase dois bilhões de dólares foram gastos em segurança!!!

14 Ver as recentes denúncias sobre os casos de doping no atletismo estadunidense em Olimpíadas anteriores e que não foram divulgados por sua própria federação.

15 "Presente Perpétuo" é uma expressão jamesiana cunhada para se referir à fragmentação da experiência vivida num mundo que é pura velocidade, impossibilitando a compreensão da corrente temporal e a percepção e formulação de um discurso coerente. 


\section{REFERÊNCIAS}

ADORNO, T. Teoria da semicultura. Educação e Sociedade. Campinas: Papirus, ano 17, n. 56, p. 388-411, dez. 1996.

ADORNO, T. ; HORKHEIMER, M. Dialética do esclarecimento. Rio de Janeiro: Zahar, 1985.

APPADURAI, A. Aprés le colonialisme. Paris: Payot, 2001.

FOUCAULT, M. As palavras e as coisas. São Paulo: Martins Fontes, 1992.

HALL, S. A identidade cultural na pós-modernidade. Rio de Janeiro: DP\&A, 2003.

HARVEY, D. A condição pós-moderna. São Paulo: Loyola, 1992.

JAMESON, F. Pós-modernismo: a lógica cultural do capitalismo tardio. São Paulo: Ática, 1997.

LEACH, E. R. Sistemas políticos da Alta Birmânia. São Paulo: EDUSP, 1996. (Clássicos)

MAUSS, M. Sociologia e antropologia. São Paulo: EPU, 1974.

RIVIÈRE, C. Os ritos profanos. Petrópolis: Vozes, 1996.

WAIZBORT, L. As aventuras de Georg Simmel. São Paulo/USP: Ed $34,2000$.

Recebido: 30 de setembro de 2004

Aprovado: 20 de outubro de 2004

Endereço para correspondência Grupo de Estudos Observatório da Mídia Esportiva

LABOMIDIA - Centro de Desportos UFSC - Campus Universitário

Bairro Trindade - Florianópolis - SC

CEP 88040-900

E-mail: giovanipires@cds.ufsc.br 